\title{
Early craniometric tools as a predecessor to neurosurgical stereotaxis
}

\author{
Demitre Serletis, MD, PhD, FRCSC, and T. Glenn Pait, MD \\ Department of Neurosurgery, Jackson T. Stephens Spine and Neurosciences Institute, University of Arkansas for Medical \\ Sciences, Little Rock, Arkansas
}

\begin{abstract}
In this paper the authors trace the history of early craniometry, referring to the technique of obtaining cranial measurements for the accurate correlation of external skull landmarks to specific brain regions. Largely drawing on methods from the newly emerging fields of physical anthropology and phrenology in the late 19th and early 20th centuries, basic mathematical concepts were combined with simplistic (yet at the time, innovative) mechanical tools, leading to the first known attempts at craniocerebral topography. It is important to acknowledge the pioneers of this pre-imaging epoch, who applied creativity and ingenuity to tackle the challenge of reproducibly and reliably accessing a specific target in the brain. In particular, with the emergence of Broca's theory of cortical localization, in vivo craniometric tools, and the introduction of 3D coordinate systems, several innovative devices were conceived that subsequently paved the way for modern-day stereotactic techniques. In this context, the authors present a comprehensive and systematic review of the most popular craniometric tools developed during this time period (prior to the stereotactic era) for the purposes of craniocerebral measurement and target localization.
\end{abstract}

http://thejns.org/doi/abs/10.3171/2015.6.JNS15424

KEY WORDS stereotactic frame; craniometry; anthropology; phrenology; cortical localization; historical vignette; history

$\mathrm{E}$ ARLY “craniometry," referring to cranial measurements for the accurate correlation of external skull landmarks to specific brain regions, laid the groundwork for sophisticated advances in modern-day neurosurgical stereotactic techniques. Largely drawing on methods from the newly emerging fields of physical anthropology and phrenology in the late 19th and early 20th centuries, basic mathematical concepts were combined with simplistic (yet at the time, innovative) mechanical tools, leading to the first known attempts at craniocerebral topography. It is important to acknowledge the pioneers of this pre-imaging epoch and appreciate the creativity and ingenuity used to solve the challenge of reproducibly and reliably accessing a specific target in the brain. In this context, we present a comprehensive and systematic review of the most popular craniometric tools developed prior to the advent of modern-day stereotactic techniques for the purposes of craniocerebral measurement and target localization.

\section{Early Anthropological Techniques}

Physical anthropology aims to study the anatomical and physiological variations of the human body. ${ }^{28}$ Anthropom- etry, referring to the scientific collection and comparative correlation of measurements of the human body (including the major bones), evolved as one of the main techniques of this discipline. ${ }^{6,57}$ Originating in the 19th century, anthropometric measurements became popularized in a variety of contexts, ranging from subjective, controversial studies of racial typing to more systematic, biometrics-related applications for law enforcement. ${ }^{59}$ In anatomical reference to external bone landmarks, it was found that simple measurements could be reliably made, including the cephalic index, i.e., the ratio of the breadth to length of the human skull. ${ }^{27}$ Such early cranial-specific measures led to the related technique of craniometry, which has enabled modern-day anthropologists to characterize the progressive evolutionary changes in the shape and size of the human head as a function of an expanded brain volume.

\section{Cranioscopy/Phrenology}

Early methods were thus developed to empirically observe, examine, and describe the human skull, such that the shape and external anatomical landmarks of the cranium could be used to infer localization of brain function. This 
skull doctrine (or Schädellehre) was termed "cranioscopy," and was popularized in the early 19th century by the German neuroanatomist and physiologist, Franz Joseph Gall (1758-1828). ${ }^{21,56}$ Cranioscopy, later known as phrenology, represented the earliest attempt at developing a methodology of functional localization and was generally met with great controversy at the time. To Gall, it was not sufficient to accept that mental ability resided in the brain; he argued that specific cognitive faculties were governed by dedicated regions (referred to as "organs") within the brain. In 1 reported case, for example, Gall insisted that the findings of frontal lobe hypertrophy and exophthalmos were correlated with superior verbal memory tasks. ${ }^{20}$ Although phrenology became fashionable in Gall's time, it was largely discredited by scientific and religious communities in the middle of the 19th century. Nevertheless, certain components of the theory have endured to establish a foundation for modern neuroscience. ${ }^{70}$

\section{Broca and the Theory of Cortical Localization}

Pierre Paul Broca (1824-1880), the famous French surgeon, anatomist, and anthropologist, further developed the field of cerebral localization. Among many other contributions to the neurosciences, he identified the role of the left inferior frontal gyrus in language articulation and conceived the notion of a dominant hemisphere (and its relation to handedness). ${ }^{3,7-9,61,69}$ In 1861, Broca first presented a now-famous case study of motor aphasia in a recently deceased patient with a lesion in the dominant (left) inferior frontal gyrus..$^{10}$ In accordance with phrenological ideology, Broca took great interest in studying abnormalities of the skull, with careful observations of bone deformations, micro- and macrocephaly, and even the spectrum of craniosynostoses. ${ }^{48,55,61}$ However, it was Broca who definitively proved through his well-known case studies that function was localized to specific cortical regions and not just to external skull landmarks, thereby making the transition from Gall's phrenology to the concepts underlying modern-day cortical localization theory. ${ }^{57,61}$ In 1880 , for example, he presented a young, plagiocephalic, mathematical prodigy capable of rapid and accurate mental calculations to the Anthropological Society of Paris. This was yet another instance in which Broca attributed the patient's advanced mental capacities to memory function (deemed the "psychological hypothesis"), rather than to his physiological differences and plagiocephalic skull morphology (i.e., the "phrenological hypothesis"), illustrating his early approach to the theory of cortical localization. ${ }^{42}$ In terms of other contributions, Broca prolifically developed more than three-dozen instruments, including specialized calipers and tools for measuring the interior of the skull (including a popular mandibular goniometer [Fig. 1]), and identified specific anatomical landmarks such as the glabella and the inion. ${ }^{5,6,12,59} \mathrm{He}$ further compiled an extensive list of craniometric techniques, including an improved method for estimating the brain volume by measuring cranial capacity on the basis of quantified packing of the skull with gun shot or mercury, as opposed to water or fine mustard seed (Fig. 2); the advent of a primitive stereographic apparatus (the stereograph, discussed below); and the development of

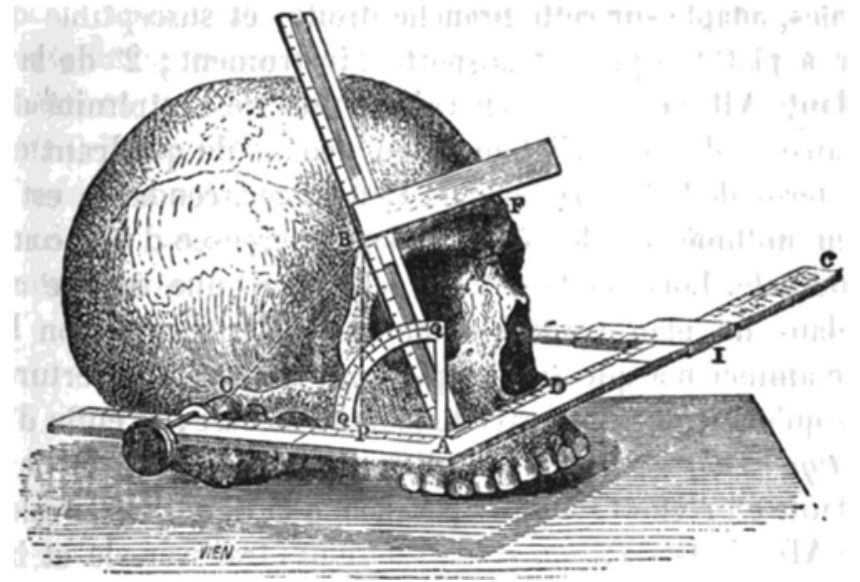

FIG. 1. Illustration of Broca's mandibular goniometer. The apparatus, consisting of a base and the goniometer itself, was made of boxwood and copper. Mobile pins could be inserted into the external ear canals to secure the box against the head. The device could be used to measure the facial angle and the dimensions of the facial triangle, delineated by a line from the basion to the alveolar point, a line from the basion to the nasal point, and a line from the nasal point to the alveolar point. Reproduced from Broca P: Description d'un nouveau goniomètre. Bull Soc Anthrop Paris 5:943-946, 1864 (Public domain). 5,6

a widely accepted system for orienting the skull in reference to the alveolo-condylian plane, among other achievements. ${ }^{11,13,14,27,50,59}$ Interestingly, Broca even developed an in vivo methodology for localizing cerebral disease via thermoencephalography, using a specialized (albeit rudimentary) crown of 6 to 8 symmetrically situated mercury thermometers capable of identifying a regional temperature difference across the head..$^{15,17,55}$ In cases of compound depressed skull fractures, a difference of $1-3^{\circ} \mathrm{C}$ over an injured region was sufficient evidence to Broca to support surgical intervention using this method. ${ }^{61}$

Of particular interest, Broca's craniograph and stereograph were the preferred methods for postmortem drawings of skull anatomy by projection, and apparently required "scarcely any skill on the part of the operator." 67 While the craniograph simply provided the outlines of the skull profile (including the location of the auditory meatus; Fig. 3), the stereograph provided additional details regarding all visible intricacies on the various surfaces of the skull. The latter tool consisted of placing a skull on a craniophore-an apparatus designed to hold the skull while measurements were directly taken-while the projection of a given surface of the skull was directly traced (Fig. $4 \mathrm{~A})$. Using the resultant image, the subsequent measurement of skull lines and curves was greatly facilitated, the latter's length typically measured using a "roulette millimétrique" (Fig. 4B) that itself was borrowed from sculptors who used it to measure the length of concave body surfaces. ${ }^{11}$ Ultimately, Broca expanded from purely skull measurements to developing a methodology for measuring skull and brain relationships, by driving pegs through the skull to record the affected (underlying) brain convolutions in postmortem studies. ${ }^{30,61}$ In this way, he paved the way for the subsequent advent of surgical craniometry, focused on defining fixed coordinates along the cranium using ex- 


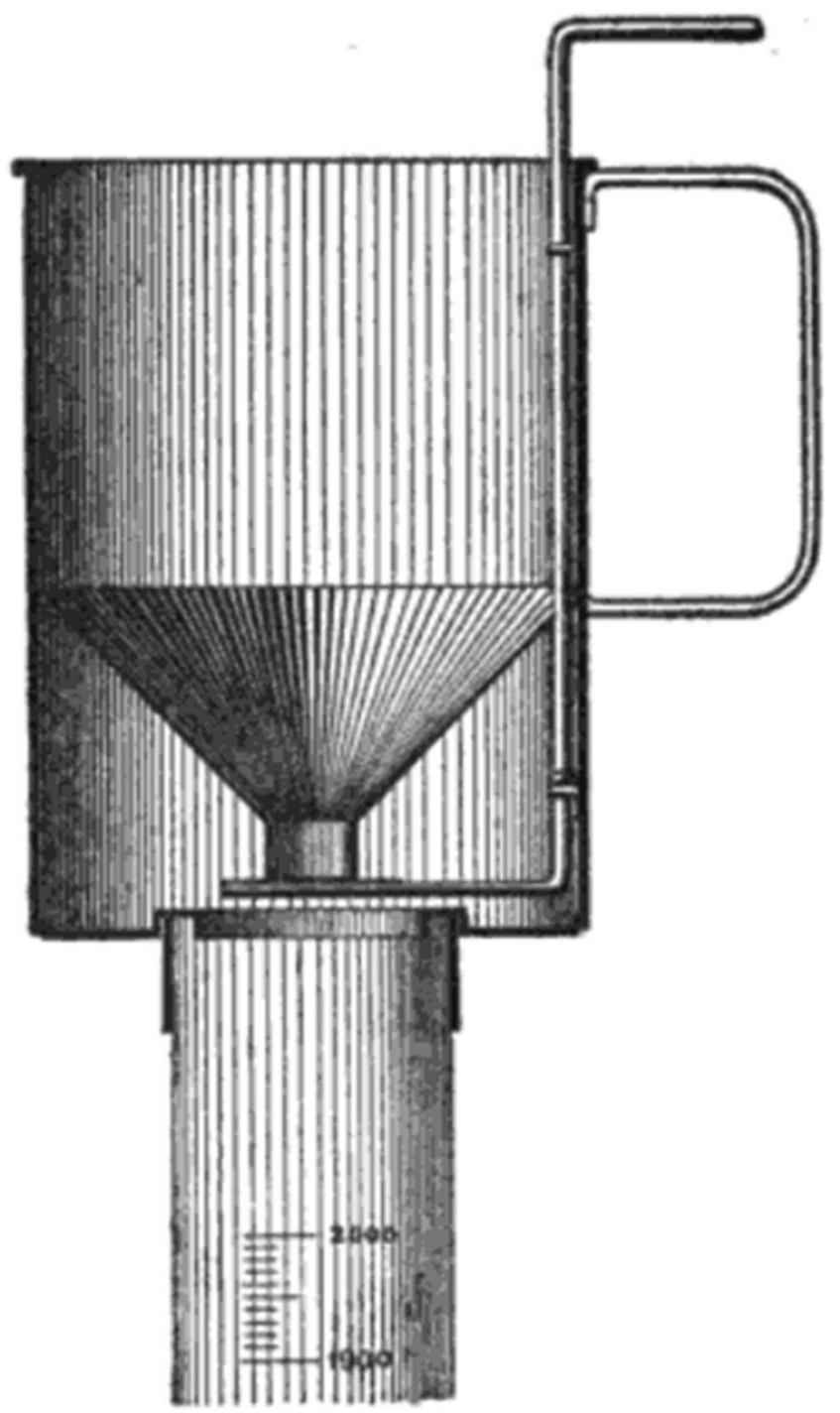

FIG. 2. Hrdlička's device for measuring cranial capacity, as an expansion upon Broca's original invention. The skull was contained within a zinc vessel and placed atop a $2 \mathrm{~L}$ graduated glass tube. It was then filled with a measurable volume of a specific compound, in this case mustard seed (as compared with Broca's original design, who preferred gun shot or mercury). Release of the lever arm would open the funnel within the vessel, allowing flow of the compound agent into the graduated cylinder for subsequent measurement of the skull capacity. Reproduced from Hrdlička A: Anthropometry. Philadelphia: Wistar Institute of Anatomy and Biology, 1920 (Public domain). ${ }^{27}$

ternal, measurable landmarks and linking these to the underlying cerebral topography. ${ }^{57}$

\section{In Vivo Craniometry for Cerebral Target Localization}

In the late 19th and early 20th centuries, at a time when radiography was just emerging as the first imaging modality, various superficial topographic localization methods arose out of neuroanatomical cadaveric-based studies. ${ }^{62} \mathrm{~A}$ few particularly well-known examples are those of Taylor and Haughton's technique for identifying the central (ro-

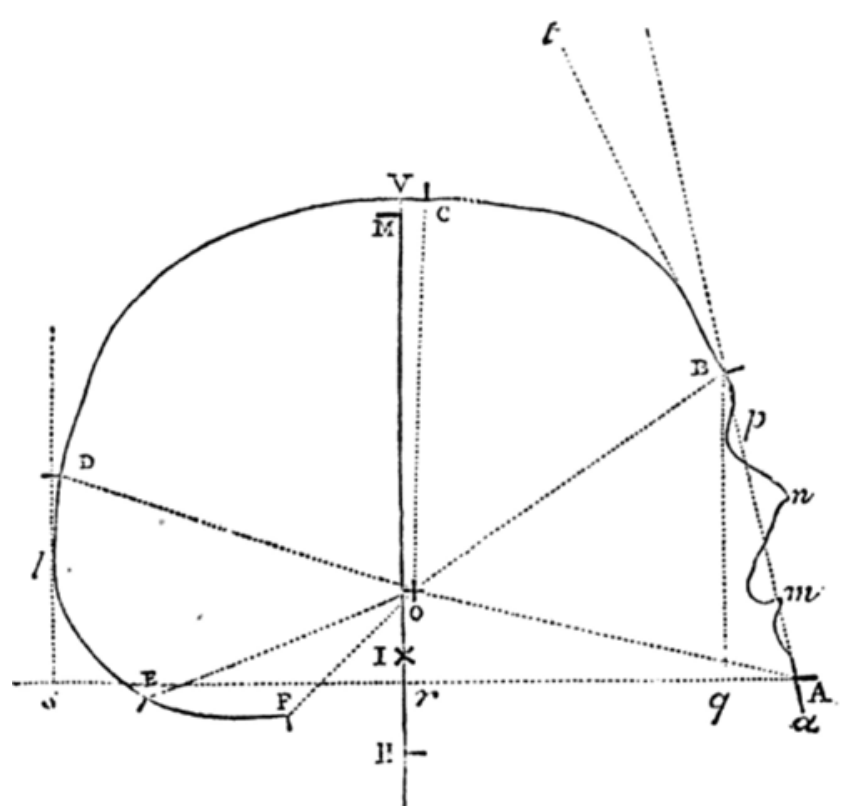

FIG. 3. Schematic of a skull profile recorded using Broca's craniograph. The "O" reference point depicts the auricular point at the center of the auditory meatus, against which multiple other measurements could be made. Reproduced from Topinard P: L'Anthropologie. Paris: C. Reinwald et Cie, 1876 (Public domain). ${ }^{67}$

landic) fissure, ${ }^{50,66}$ in addition to Keen's, Fraser's, and Kocher's access sites for puncture of the lateral ventricle. ${ }^{31,35}$ Additionally, several more elaborate skull craniographs were developed around this time, an example of which is shown in Fig. 5. ${ }^{65}$ Moreover, a detailed description of additional puncture sites for exploratory brain aspiration was outlined in 1904 by Neisser and Pollack (using Kocher's craniometer, as discussed below); the latter also recognized the associated risk for injury to important arterial and venous vessels with these procedures (Fig. 6). . $^{31,41}$

In parallel to these developments, attempts at functional localization were further advanced by the important introduction of electricity in experimental studies. Most notably, an experiment conducted in 1870 by Gustav Theodor Fritsch (1838-1927), an anatomist, anthropologist, and physiologist, and the neuropsychiatrist Julius Eduard Hitzig (1838-1907) showed evidence for excitable motor cortex in a dog, as a result of direct electrical stimulation to the brain itself. ${ }^{22,24}$ Sir David Ferrier (1843-1928), a Scottish neurologist-psychologist, conducted additional animal experimentation using electrical (Faradic) stimulation and lesioning in the brains of birds, cats, guinea pigs, dogs, rabbits, and macaques. His studies suggested that motor and sensory functions were consistently represented in an organized fashion within the cerebral cortex, furthering the modern-day understanding of the motor strip, a notion built upon the ideas of his mentor, John Hughlings Jackson, and those of Broca, among others. ${ }^{46,52}$

It is in this context of newly recognized surface landmarks and an enhanced understanding of the location of the motor strip that the necessity was born for mechanical devices that would permit reliable, accurate, and reproducible measurements for in vivo target localization across 


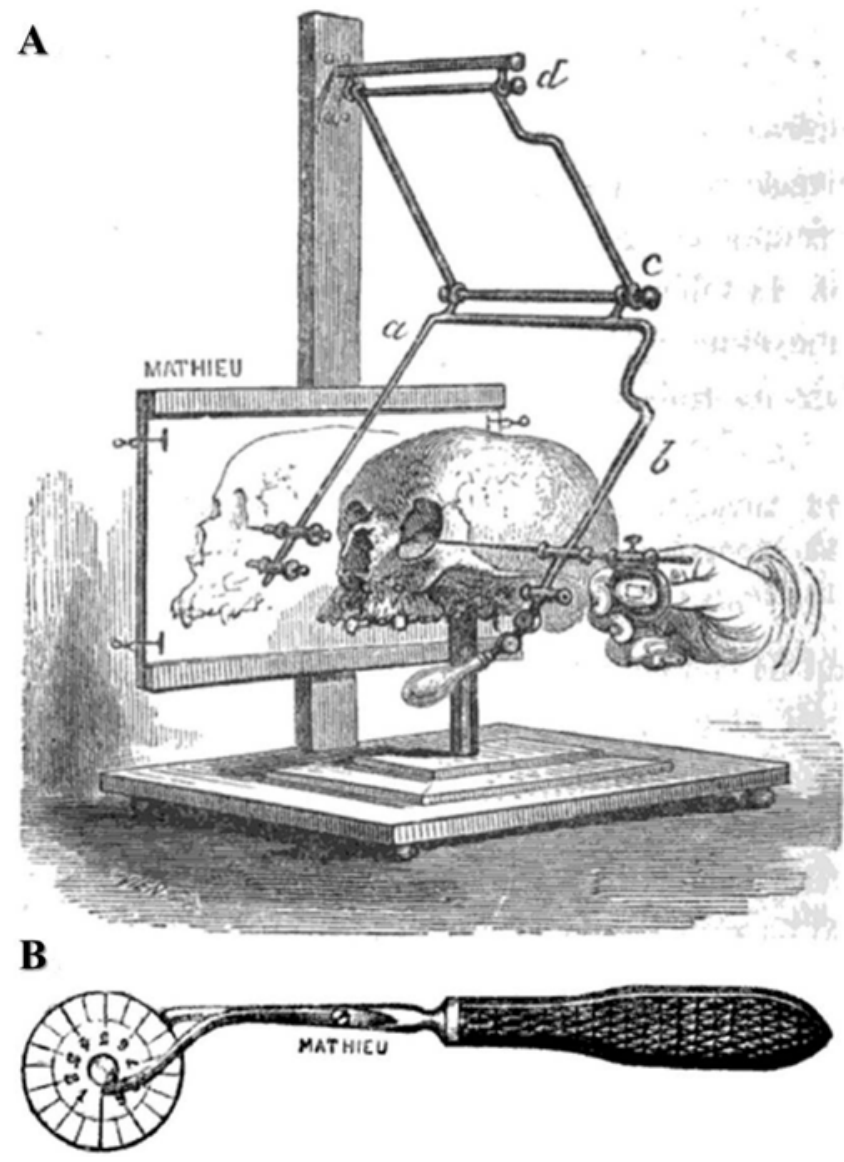

FIG. 4. A: Illustration of Broca's stereograph, depicting a skull seated on a craniophore as shown, which itself could be rotated depending on which view was desired. This device could systematically delineate skull outlines as projected tracings with measurable straight lines, angles, and curves, permitting accurate cranial measurements down to the millimeter. Reproduced from Topinard P: L'Anthropologie. Paris: C. Reinwald et Cie, 1876 (Public domain). ${ }^{67}$ B: Traced curves were routinely measured through use of a roulette millimétrique, or graduated wheel. Reproduced from Broca P: Sur l'endocrâne. Nouveaux instruments destinés à étudier la cavité crânienne sans ouvrir le crâne. Bull Soc Anthrop Paris 8:352-383, 1873 (Public domain).11

varying cranial shapes and dimensions. One such early device for readily locating the Rolandic fissure, Wilson's cyrtometer, consisted of a flexible, T-shaped metal scale secured around the cranium in coronal fashion, with an anteroposterior band extending from the glabella to the inion (Fig. 7). ${ }^{26,44} \mathrm{~A}$ third projecting strip was fixed at an angle of anywhere between $61^{\circ}$ and $67^{\circ}$, and could be bent down directly to yield the course of the rolandic fissure. ${ }^{29,45}$ Similar cephalometers were developed by Krönlein and Köhler using measurements that were simple and easily remembered for the purposes of localizing the rolandic and sylvian fissures (and ultimately, the motor region).$^{49} \mathrm{Of}$ note, Sir Victor Alexander Haden Horsley also reportedly developed a similar "Rolandic fissure meter." 34,40

In large part due to correspondence with Horsley, the Swiss surgeon Emil Theodor Kocher (1841-1917) developed a substantially improved craniometer consisting of 2 flexible, nickel-plated, steel bands with gradient markings (in centimeters) situated around the equator of the head and along the sagittal plane from the glabella to the external occipital protuberance (Fig. 8) ${ }^{35,57}$ Kocher's device had screws to fix the bands in a rigid position, with a third band situated along the sagittal strip that could be adjusted to any angle, and with a fourth such strip that encircled the cranium in oblique fashion from the glabella to the lambda (to help identify the sylvian fissure). In comparison with its earlier predecessors, Kocher's craniometer could be easily applied to different head shapes and sizes in any age group, and was hailed by Harvey Cushing (among many others) as one of the best devices for craniocerebral localization of its time. ${ }^{18,31,36,57}$

\section{Emergence of 3D Coordinate Systems}

Expanding on these early craniometric methodologies, a major advance in instrumentation for cranial localization in humans was the apparatus devised by the anatomist Dmitrii Zernov (1843-1917) and his pupil, Nikolai Altukhov, during the late 19th century in Russia. ${ }^{19,39}$ Zernov's primitive aluminum encephalometer comprised a horizontal ring secured at 5 sites to the patient's head, with a perpendicular band running along the coronal plane and with an adjustable meridian arclike device in the sagittal plane (Fig. 9). ${ }^{32,33,71-73}$ Spatial localization with this device was achieved using a spherical coordinate system (measured in degrees of longitude and latitude), and the system could also be used to determine the curvature of the skull. ${ }^{25} \mathrm{Al}-$ though the device never gained widespread use and was likely suitable only for superficially situated lesions, the apparatus appears to have been the first used clinically for localization and an important forerunner of today's stereotactic frame. Grigorii Ivanovich Rossolimo (1860-1928), a Russian neurologist and one of the founders of pediatric neurology and psychiatry, subsequently developed a more refined system of measuring the surface of the head's 3D topography in 1907. $25,51,53,54$ Rossolimo modified Zernov's frame into a sphere-shaped helmet called the "cerebral topographer," which also included a soldered, hollow aluminum hemisphere (consisting of an engraved map of brain fissures, gyri, and subcortical structures), with small perforations interspaced along graduated parallels and meridians through which ink markings could be traced along the head surface (Fig. 10). This tool permitted the encephalometric marking of any cerebral structure to the overlying scalp, without restriction by the frame's arcs. $25,32,33,54$

Ultimately, the mathematical use of spherical coordinates in these earlier devices gave way to implementation of the tricoordinate Cartesian system. As early as 1873, the physiologist Carl Dittmar (1844-1920) reported on a simplistic guiding device for his instruments, capable of producing consistent, circumscribed lesions in the rat medulla oblongata (specifically, within the bulbar vasomotor centers) ${ }^{1,43,47}$ Although some have offered that this device is the first historical sign of development leading to a stereotactic frame, it was not spatially coregistered in today's stereotactic sense. ${ }^{4}$

Arising out of subsequent elaborate studies of deepbrain structures in the cat and monkey, however, Sir Victor Alexander Haden Horsley (1857-1916; neurophysiologist 
A

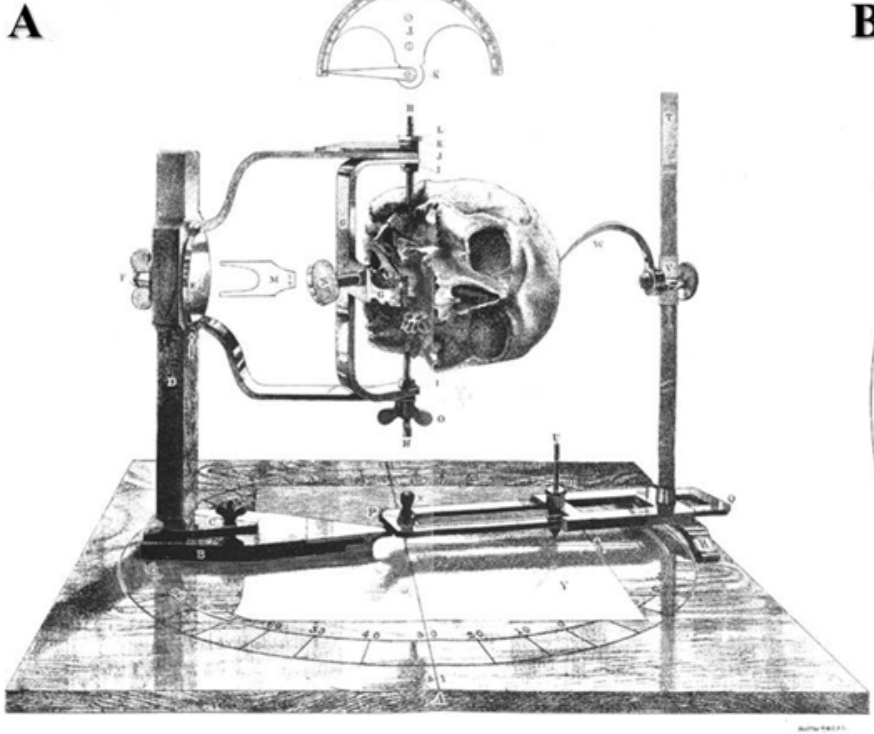

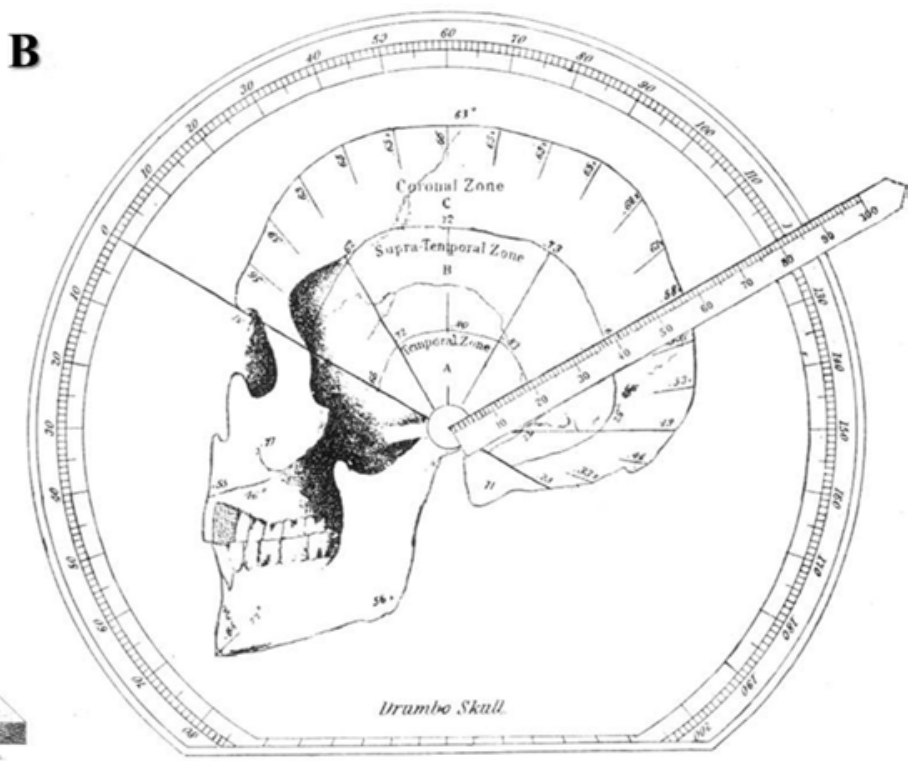

FIG. 5. Example of a craniometer and craniometric methods as developed by the Irish apothecary and craniologist, John Grattan (1800-1871). A: Drawing of an elaborate craniometer, permitting accurate outline tracings of the median (midline) section of the skull, but also transverse sectional outlines at any other desired point, by adjusting the vertical bar at position " $E$ " in the diagram. B: Accurate measurements taken across various sagittal sectional outlines from a skull, showing the function of the craniometer device. Reproduced from Symington J: John Gratton's craniometer and craniometric methods. J Anat Physiol 38:259-274, 1904 (Public domain). ${ }^{63}$

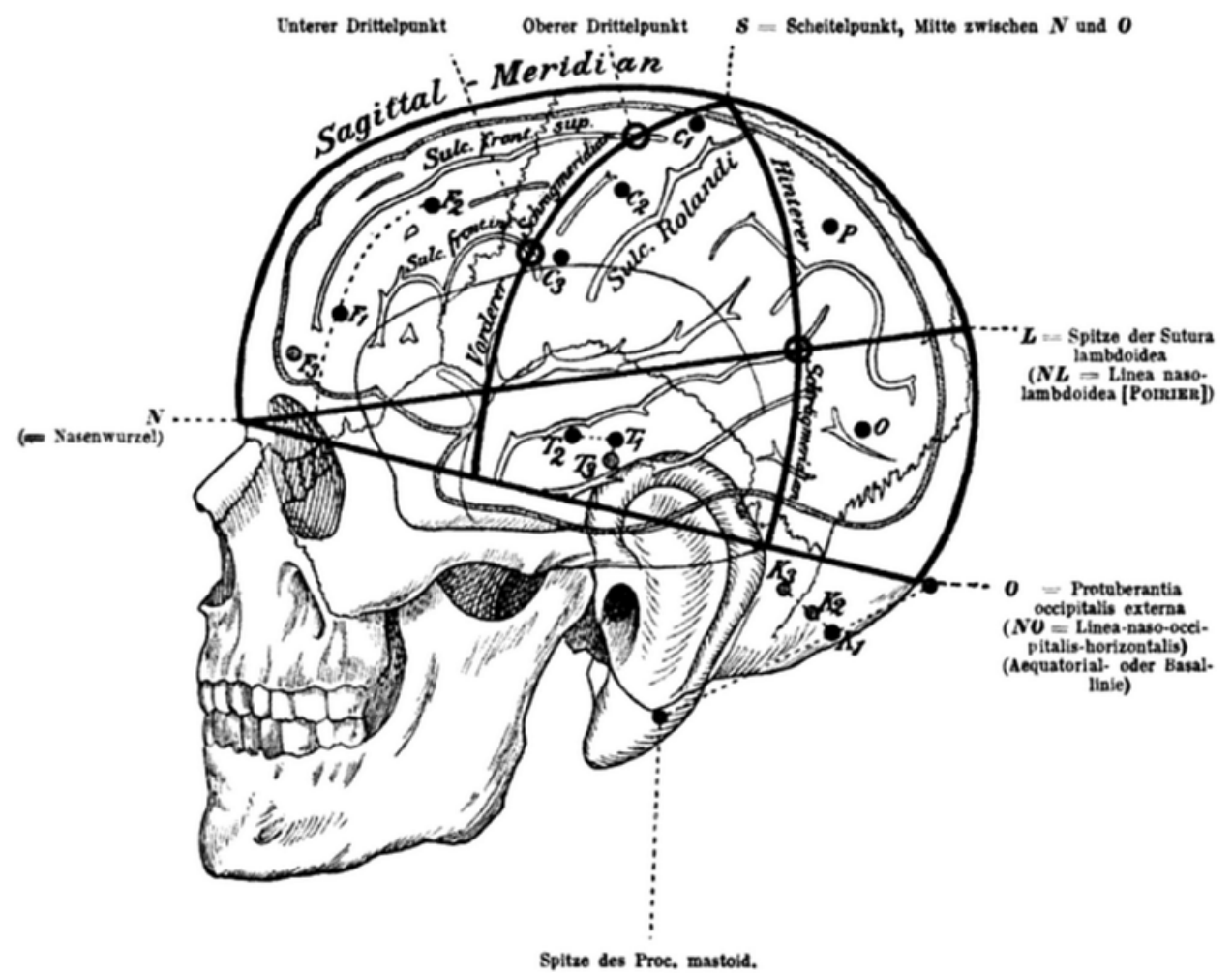

FIG. 6. Neisser and Pollack's proposed landmarks for exploratory brain puncture. The darkened black lines depict Kocher's craniometer (further illustrated in Fig. 8), superimposed here for reference. Open circles reveal suggested points for aspiration in cases of suspected brain abscess, and the solid, black circles reveal suggested puncture sites for aspiration of the various lobes of the brain. Reproduced from Neisser E, Pollack K: Die Hirnpunktion. Probepunktion und Punktion des Gehirnes und seiner Häute durch den intakten Schädel. Mitt Grenzgeb Med Chir 13:807-896, 1904 (Public domain). ${ }^{41}$ 

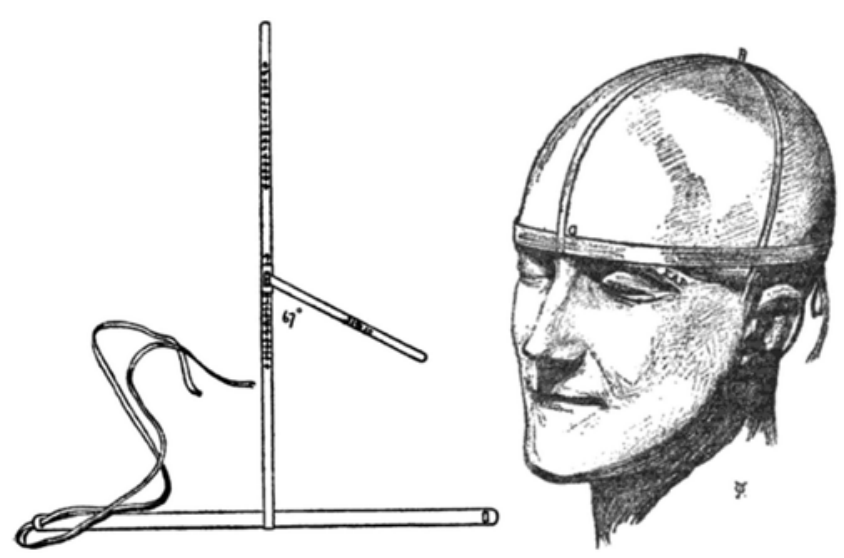

FIG. 7. Schematic illustrating Wilson's cyrtometer, consisting of a scale for localizing the rolandic fissure. The device consisted of a flexible, T-shaped metallic band secured in the coronal plane, an anteroposterior band extending from the glabella to the inion, and a third strip (fixed at the shown angle of $67^{\circ}$ ) that could be bent over the cranium to reveal the course of the rolandic fissure. Reproduced from Park R: Surgery of the brain, based on the principles of cerebral localization. Trans Cong Am Phys Surg 1:285-328, 1889 (Public domain). ${ }^{45}$

and neurosurgeon) and the mathematician Robert Henry Clarke (1850-1926) developed the first practical, Cartesian-based, stereotactic device that ultimately paved the way for modern stereotaxy. ${ }^{19}$ The term "stereotaxis" was originally derived by Horsley and Clarke, referring to the Greek stereos (meaning "solid") and taxis (meaning "ordered" or "organized"). ${ }^{19,49}$ The Horsley-Clarke frame allowed for strategic direction of an electrode into cortical and subcortical structures, with guidance based on the Cartesian coordinate system. It eventually served as the basis for a modification by the Canadian neuroanatomist and neurophysiologist, Aubrey Mussen (1873-1975) in 1918, who developed it for human use.,47 Eventually, however, Ernst A. Spiegel, Henry T. Wycis, Vernon Marks, and A.J. Lee presented their version of the Horsley-Clarke frame for use on humans in 1947, describing the first report of

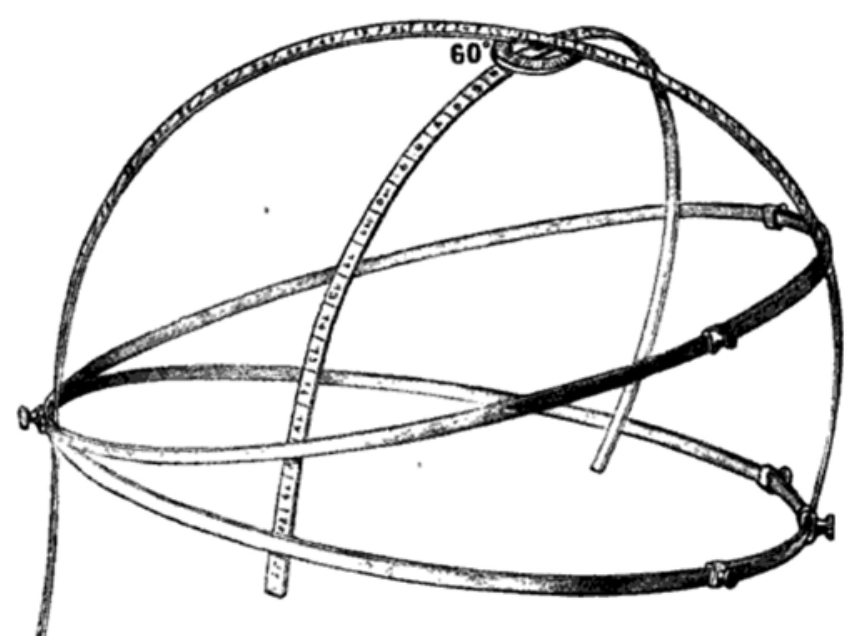

FIG. 8. Illustration of Kocher's craniometer. Reproduced from Kocher T: Text-book of Operative Surgery. London: Adam and Charles Black, 1903 (Public domain). ${ }^{35}$

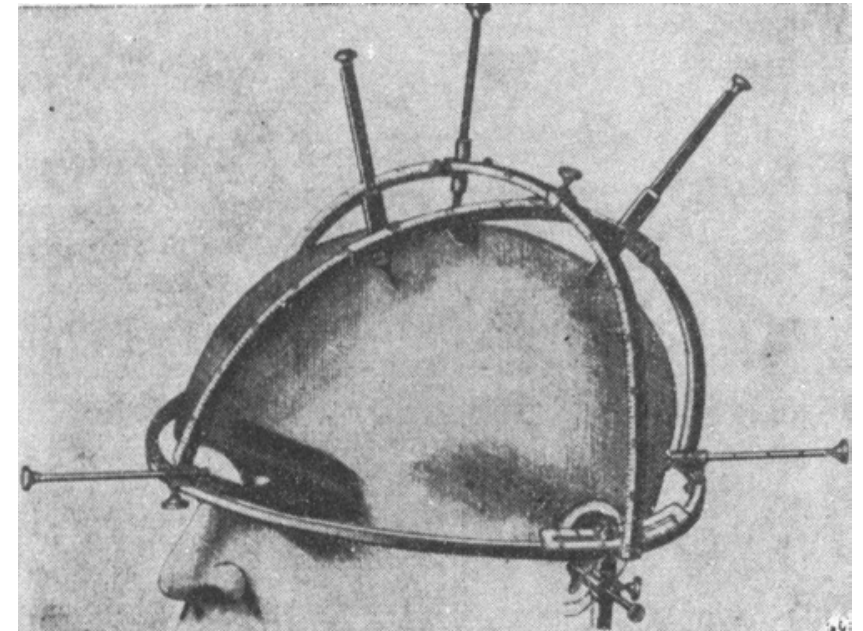

FIG. 9. Zernov's encephalometer, one of the first known stereotactic devices for use in human patients, provided spatial localization on the basis of spherical coordinates. Reproduced from Kandel' Él, Shchavinskii YV: First stereotaxic apparatus created by Russian scientists in the 19th century. Biomed Eng (NY) 7:121-124, 1973. ${ }^{32}$ With kind permission from Springer Science and Business Media.

stereotactic operative techniques on the human brain. This definitively marked the starting point of the field of stereotactic neurosurgery. ${ }^{4,60}$ In close succession, further innovations were soon conceived by other eminent pioneers in the field of stereotaxy, including Jean Talairach, Jean Bancaud, Hirotaro Narabayashi, and Lars Leksell, among others. ${ }^{2,19,37,38,64,65,68}$ In this way, the modern era of framebased and frameless stereotaxy was explosively propelled into the 21 st century. ${ }^{16,23,58}$

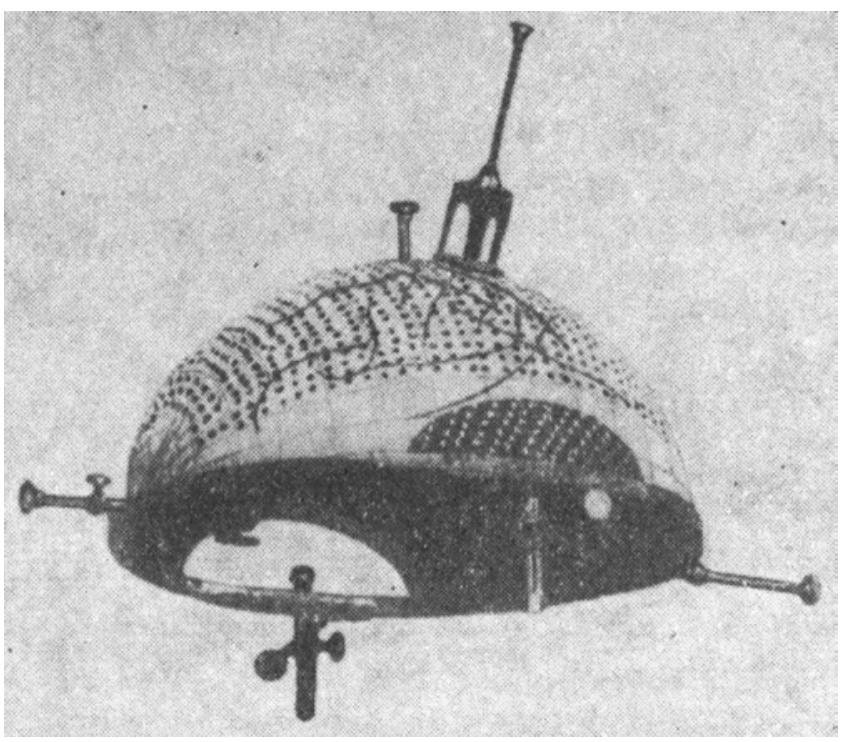

FIG. 10. Rossolimo's cerebral topographer, a spherical helmet modified from Zernov's original encephalometer, facilitated spherical coordinate measurements of cerebral structures to the overlying scalp. Reproduced from Kandel' Él, Shchavinskii YV: First stereotaxic apparatus created by Russian scientists in the 19th century. Biomed Eng (NY) 7:121-124, 1973. ${ }^{32}$ With kind permission from Springer Science and Business Media. 


\section{Conclusions}

Early craniometric techniques stemming from physical anthropology and phrenology laid the groundwork for subsequent developments in craniocerebral localization techniques. The combination of basic mathematical concepts with simple (yet elegant) mechanical tools led to the first attempts at mapping the surface topography of the brain, and the challenge of consistently accessing a specific target on the brain's surface. Owing to the inventive and pioneering minds of the pre-imaging epoch, subsequent efforts at localization eventually led to the modern-day, 3D coordinate system-based methods that are now in widespread use. Given the tremendous changes observed in our discipline over the last 200 hundred years, it is exciting to anticipate what potentially lies in store for future patients undergoing stereotactic neurosurgical procedures.

\section{References}

1. al-Rodhan NR, Kelly PJ: Pioneers of stereotactic neurosurgery. Stereotact Funct Neurosurg 58:60-66, 1992

2. Bancaud J, Talairach J, Bonis A, Schaub C, Szikla G, Morel P, et al: La Stéréoélectroencéphalographie dans l'Épilepsie: Informations Neurophysiopathologiques Apportées par l'Investigation Fonctionnelle Stereotaxique. Paris: Masson, 1965

3. Berker EA, Berker AH, Smith A: Translation of Broca's 1865 report. Localization of speech in the third left frontal convolution. Arch Neurol 43:1065-1072, 1986

4. Blomstedt P, Olivecrona M, Sailer A, Hariz MI: Dittmar and the history of stereotaxy; or rats, rabbits, and references. Neurosurgery 60:198-202, 2007

5. Broca P: Description d'un nouveau goniomètre. Bull Soc Anthrop Paris 5:943-946, 1864

6. Broca P: Mémoires d’Anthropologie. Paris: C. Reinwald, 1871

7. Broca P: Nouvelle observation d'aphémie produite par une lésion de la moitié postérieure des deuxième et troisième circonvolutions frontales gauches. Bull Soc Anat Paris 6:398-407, 1861

8. Broca P: Remarques sur le siége de la faculté du langage articulé, suivies d'une observation d'aphémie (perte de la parole). Bull Soc Anthrop Paris 6:330-357, 1861

9. Broca P: Siége de la faculté du langage articulé: Deux cas d'aphémie traumatique produite par des lésions de la troisième circonvolution frontale gauche. Bull Soc Anat Paris 5:213-217, 1864

10. Broca P: Sou les projections de la tête et sur un nouveau procédé de céphalométrie. Bull Soc Anthrop Paris 3:534544, 1862

11. Broca P: Sur l'endocrâne. Nouveaux instruments destinés à étudier la cavité crânienne sans ouvrir le crâne. Bull Soc Anthrop Paris 8:352-383, 1873

12. Broca P: Sur l'inion ou point iniaque, et ses variations suivant les races. Bull Soc Anthrop Paris 3:18-20, 589-591, 1862

13. Broca P: Sur le plan horizontal de la téte et sur la méthode trigonométrique. Bull Soc Anthrop Paris 8:48-92, 1873

14. Broca P: Sur le stéreographe, nouvel instrument craniographique destiné à desiner tous les détails du relief des corps solides. Mém Soc Anthrop Paris 3:99-124, 1868

15. Broca P: Sur les températures, morbides locales. Bull Acad Méd 8:1331-1347, 1879

16. Cardinale F, Cossu M, Castana L, Casaceli G, Schiariti MP, Miserocchi A, et al: Stereoelectroencephalography: surgical methodology, safety, and stereotactic application accuracy in 500 procedures. Neurosurgery 72:353-366, 2013

17. Cohen L, Smith MJ, Leroux-Hugon V: Paul Broca's thermometric crown. J Neurol Neurosurg Psychiatry 75:32, 2004
18. Cushing H: Surgery of the head, in Keen W (ed): Surgery: Its Principles and Practice. Philadelphia: WB Saunders, 1908, Vol 3, pp 217-276

19. Dagi TF: History of stereotactic surgery, in Greenblatt SH (ed): A History of Neurosurgery in its Scientific and Professional Contexts. Park Ridge, IL: The American Association of Neurological Surgeons, 1997, pp 401-438

20. De Ridder D: A short history of neurosurgical localization. World Neurosurg 80:479-481, 2013

21. Duichin M: [Anatomists, philosophers, "head hunters": Gall, Kant and the early days of phrenology.] Physis Riv Int Stor Sci 48:103-126, 2011-2012 (Ital)

22. Fritsch G, Hitzig E: Electric excitability of the cerebrum (Uber die elektrische Erregbarkeit des Grosshirns). Epilepsy Behav 15:123-130, 2009

23. Gonzalez-Martinez J, Bulacio J, Alexopoulos A, Jehi L, Bingaman W, Najm I: Stereoelectroencephalography in the "difficult to localize" refractory focal epilepsy: early experience from a North American epilepsy center. Epilepsia 54:323-330, 2013

24. Gross CG: The discovery of motor cortex and its background. J Hist Neurosci 16:320-331, 2007

25. Grunert P: From the idea to its realization: the evolution of minimally invasive techniques in neurosurgery. Minim Invasive Surg 2013:171369, 2013

26. Hare A: Lectures on cranial surgery. Lancet 131:407-409, 1888

27. Hrdlička A: Anthropometry. Philadelphia: Wistar Institute of Anatomy and Biology, 1920

28. Hrdlička A: Physical Anthropology: Its Scope and Aims; Its History and Present Status in the United States. Philadelphia: Wistar Institute of Anatomy and Biology, 1919

29. Hughes CH: Lectures in Neurology, Neuriatry, Psychology and Psychiatry. St. Louis: Hughes \& Co., 1903

30. Jensen RL, Stone JL, Hayne RA: Introduction of the human Horsley-Clarke stereotactic frame. Neurosurgery 38:563567,1996

31. Johnson A: Operative Therapeusis. New York: D. Appleton and Company, 1915

32. Kandel' ÉI, Shchavinskii YV: First stereotaxic apparatus created by Russian scientists in the 19th century. Biomed Eng (NY) 7:121-124, 1973

33. Kandel EI, Schavinsky YV: Stereotaxic apparatus and operations in Russia in the 19th century. J Neurosurg 37:407-411, 1972

34. Keen WW: Discussion on intra-cranial lesions: Introductory remarks of the following questions. Trans New York State Med Assoc 7:86-110, 1890

35. Kocher T: Text-book of Operative Surgery. London: Adam and Charles Black, 1903

36. Krause F: Surgery of the Brain and Spinal Cord Based on Personal Experiences. New York: Rebman, 1912

37. Leksell L: A stereotaxic apparatus for intracerebral surgery. Acta Chir Scand 99:229-233, 1949

38. Leksell L: The stereotaxic method and radiosurgery of the brain. Acta Chir Scand 102:316-319, 1951

39. Lichterman BL: Roots and routes of Russian neurosurgery (from surgical neurology towards neurological surgery). J Hist Neurosci 7:125-135, 1998

40. Mills CK, Frazier CH: The motor area of the human cerebrum, its position and subdivisions, with some discussion of the surgery of this area. Univ Pa Med Bull 18:134-147, 1905

41. Neisser E, Pollack K: Die Hirnpunktion. Probepunktion und Punktion des Gehirnes und seiner Häute durch den intakten Schädel. Mitt Grenzgeb Med Chir 13:807-896, 1904

42. Nicolas S, Guida A, Levine Z: Broca and Charcot's research on Jacques Inaudi: the psychological and anthropological study of a mental calculator. J Hist Neurosci 23:140-159, 2014 
43. Olivier A, Bertrand G, Picard C: Discovery of the first human stereotactic instrument. Appl Neurophysiol 46:84-91, 1983

44. Park R: Diseases and Injuries of the Head. Philadelphia: Lea Brothers \& Co., 1895, Vol 2

45. Park R: Surgery of the brain, based on the principles of cerebral localization. Trans Cong Am Phys Surg 1:285328,1889

46. Pearce JM: Sir David Ferrier MD, FRS. J Neurol Neurosurg Psychiatry 74:787, 2003

47. Picard C, Olivier A, Bertrand G: The first human stereotaxic apparatus. The contribution of Aubrey Mussen to the field of stereotaxis. J Neurosurg 59:673-676, 1983

48. Pozzi S: Paul Broca. Rev Antropol 2:577-608, 1880

49. Rahman M, Murad GJ, Mocco J: Early history of the stereotactic apparatus in neurosurgery. Neurosurg Focus 27(3):E12, 2009

50. Reis CV, Sankar T, Crusius M, Zabramski JM, Deshmukh P, Rhoton AL Jr, et al: Comparative study of cranial topographic procedures: Broca's legacy toward practical brain surgery. Neurosurgery 62:294-310, 2008

51. Rossolimo G: Mozgovoi topograf. Zhurnal Nevropatologii I Psikhiatrii Imeni Korsakova 7:640-644, 1907

52. Sandrone S, Zanin E: David Ferrier (1843-1928). J Neurol 261:1247-1248, 2014

53. Satran R: G.I. Rossolimo (1860-1928). J Neurol 252:14231424,2005

54. Satran R: G.I. Rossolimo (1860-1928): Neurologist and public benefactor. J Hist Neurosci 16:65-73, 2007

55. Schiller F: Paul Broca: Founder of French Anthropology, Explorer of the Brain. Berkeley: University of California Press, 1979

56. Schultz DP, Schultz SE: A History of Modern Psychology, ed 9. Fort Worth: Harcourt College Publishers, 2003

57. Schültke E: Theodor Kocher's craniometer. Neurosurgery 64:1001-1005, 2009

58. Serletis D, Bulacio J, Bingaman W, Najm I, GonzálezMartínez J: The stereotactic approach for mapping epileptic networks: a prospective study of 200 patients. J Neurosurg 121:1239-1246, 2014

59. Spencer F: History of Physical Anthropology. New York: Garland Publishing, 1997

60. Spiegel EA, Wycis HT, Marks M, Lee AJ: Stereotaxic apparatus for operations on the human brain. Science 106:349350,1947

61. Stone JL: Paul Broca and the first craniotomy based on cerebral localization. J Neurosurg 75:154-159, 1991

62. Sun A, Hou L, Cheshier S, Sedrak M, Tse V: The accuracy of topographical methods in determining central sulcus: a statistical correlation between modern imaging data and these historical predications. Cureus 6:e186, 2014
63. Symington J: John Gratton's craniometer and craniometric methods. J Anat Physiol 38:259-274, 3, 1904

64. Talairach J, Bancaud J: Lesion, "irritative" zone and epileptogenic focus. Confin Neurol 27:91-94, 1966

65. Talairach J, Bancaud J, Bonis A, Szikla G, Tournoux P: Functional stereotaxic exploration of epilepsy. Confin Neurol 22:328-331, 1962

66. Taylor AJ, Haughton VM, Syvertsen A, Ho KC: TaylorHaughton line revisited. AJNR Am J Neuroradiol 1:55-56, 1980

67. Topinard P: L'Anthropologie. Paris: C. Reinwald et Cie, 1876

68. Uchimura Y, Narabayashi H: [Stereoencephalotomy.] Psychiat Neurol Jpn 52:265-270, 1951

69. Walker AE: The development of the concept of cerebral localization in the nineteenth century. Bull Hist Med 31:99121,1957

70. Wolfgang R, Michael N: [Franz Joseph Gall and his "talking skulls" established the basis of modern brain sciences.] Wien Med Wochenschr 158:314-319, 2008

71. Zernov D: Encephalometer: a device for determination of the location of brain parts of living human. Proc Soc Physicomedicine 2:70-86, 1889

72. Zernov D: Entsefalometr - ustroistvo dlya lokalizatsii mozgovych structur u zhivogo cheloveka. Predvaritel'noe soobshenie. Trudy Fiziko-meditsynskogo Obshestva Moscovskogo Universiteta 2:70-80, 1889

73. Zernov D: L'encéphalométre. Rev Gén Clin Thér 19:302, 1890

\section{Disclosures}

The authors report no conflict of interest concerning the materials or methods used in this study or the findings specified in this paper.

\section{Author Contributions}

Conception and design: both authors. Acquisition of data: both authors. Analysis and interpretation of data: Serletis. Drafting the article: Serletis. Critically revising the article: both authors. Reviewed submitted version of manuscript: both authors. Approved the final version of the manuscript on behalf of both authors: Serletis. Administrative/technical/material support: both authors.

\section{Correspondence}

Demitre Serletis, UAMS, Department of Neurosurgery, 4301 W. Markham St., Slot \#507, Little Rock, AR 72205. email: dserletis@uams.edu. 